\title{
Open-label uncontrolled pilot study on antipsoriatic activity of
}

\section{Rosa hemisphaerica}

\begin{abstract}
Lana Y. Muttalib * Aveen N. Adham * $\quad$ Salah Abu Baker ** Alaadin M. Naqishbandi *

Abstract

Background and objective: Rosa hemisphearica (Rosaceae) is highly cultivated worldwide as an ornamental plant and medicinally have an antibacterial and antioxidant effect. This study aimed to investigate clinically and histopathologically the anti-inflammatory activity of Rosa hemisphearica in psoriasis and to correlate the anti-inflammatory activity with the active constituents in the plant by the phytochemical study.

Methods: In this open-label uncontrolled pilot study, a topical preparation of $R$. hemisphearica stem extract was used by 20 patients suffering from psoriasis for three weeks. Three histopathological slides for each patient, one each week for three weeks was done for anti-inflammatory response evaluation. Subsequently, total phenolic content was measured followed by thin layer chromatography (TLC) and high-performance liquid chromatography (HPLC) analysis for the identification of phenolic acid content in the stem.

Results: By histopathological examination revealed that both Munro's and Kogoj's abscesses were gradually disappeared, the granular layer gradually restored to normal and the inflammatory cells gradually reduced in number prominently polymorph (neutrophils) and eventually histocytes disappeared. Total phenolic contents in R. hemisphearica stem extract were determined as $205.625 \mu \mathrm{g}$ gallic acid equivalentl each $\mathrm{gm}$ of the sample extract, TLC, and HPLC results showed the presence of rosmarinic acid in the stem extract. On quantitative HPLC analysis, the percentage of rosmarinic acid in the stem extract was 0.024 with a retention time (Rt) of $3.4 \mathrm{~min}$. The proposed HPLC method was found to be linear, accurate and precise.
\end{abstract}

Conclusion: The organic solvent extract of R. hemisphearica stem showed a significant reduction in an inflammatory cell among psoriatic patients under study. Rosmarinic acid was identified by TLC and HPLC as important phenolic acid constituents.

Keywords: Rosa hemisphearica; Antipsoriatic; HPLC; TLC; Total phenolic.

\section{Introduction}

Rosa hemisphearica ( $R$. hemisphaerica) (Rosaceae) is an erect shrub 1-2m height with grey-green leaves of five to seven leaflets. Flowers of this plant large pale yellow, native to Asia Minor and Southwest Asia, also grow in Iran, especially in Kordestan, Azarbayejan, and Semnan. ${ }^{1,2}$ Medicinally have an antioxidant and antibacterial effect. $^{3}$ Previous research works on Rosa spp. revealed antibacterial activity, ${ }^{4}$ relaxant effects of the ethanolic extract and essential oils of R.damascena on tracheal chains of guinea pigs were documented. $^{5}$ Also, extracts from the fruits of R.canina were shown to possess significant inhibitory activity against inflammation by inhibition of p-benzoquinone-induced writhing in mice. ${ }^{6}$ $R$. hemisphaerica flowering parts yields colorless oil. The major constituents are heneicosane $(32 \%)$, nonadecane $(30 \%)$, 9-nonadecene $(10.5 \%)$, and tricosane $(8.3 \%) .{ }^{7} \mathrm{R}$. hemisphaerica stem extract is used traditionally in Kurdistan for the topical treatment of inflammatory skin

* Department of Pharmacognosy, College of Pharmacy, Hawler Medical University, Erbil, Iraq.

** Department of Pathology, College of Medicine, Hawler Medical University, Erbil, Iraq. 
https://doi.org/10.15218/zjms.2017.014

diseases. Psoriasis is a chronic skin condition that is often associated with systemic manifestations, develop at any age, but onset is most likely between 15 and 30 years of age, and the prevalence is about equal between men and women. Many stressful physiologic and psychological events and environmental factors are associated with the onset and worsening of the condition. Diagnosis is based on the typical erythematous, scaly skin lesions, often with additional manifestations in the nails and joints. ${ }^{8}$ From literature survey, there was no previous research work neither on the activity of stem part of the plant nor its active constituents. This study is an in-vitro evaluation of the anti-inflammatory activity of $R$. hemisphaerica in patients with psoriasis, and bioassay guided identification of the main active constituents in the extract by thin layer chromatography (TLC) and high-performance liquid chromatography (HPLC).

\section{Methods}

\section{Plant materials}

$R$. hemisphaerica stem was collected from the natural rose gardens of Erbil, Kurdistan region, Iraq. The stem was cleaned, cut into small pieces, air dried under shade for 5-7days and stored in bottles until using. The identity of the plant was confirmed by assistant professor Saeed FJ from the College of Education, University of Salahaddin, Iraq. A voucher specimen is stored at the Department of Pharmacognosy, Hawler Medical University, Iraq (Voucher No.A4).

\section{Antipsoriatic evaluation}

A Hundred grams of the powdered crude plant material was extracted with $(500 \mathrm{ml})$ $80 \%$ ethanol using an ultrasonic assisted extractor, was concentrated using rotary vapor machine and was kept dried at $4^{0} \mathrm{C} .{ }^{9}$ Topical preparation was prepared for antipsoriatic evaluation using dried extract in Vaseline $20 \%$ (w/w). ${ }^{10}$ In this open-label uncontrolled pilot study, ${ }^{11}$ the topical extract preparation was used by 20 patients for three weeks, a skin biopsy was taken from all of them before treatment, and after treatment for three consecutive weeks, totally four slides for each patient were done. The samples were processed for biopsy through fixation in 10\% neutral formalin and dehydration in ethanol, cleaning by xylose, embedded in paraffin, blocked, sectioned by microtome 2-5 micron, stained by Hematoxylin and Eosinstainsand examined by light microscopy Euromax HBA.

\section{Ethical clearance}

The protocol was duly submitted to the Ethics Committee of the College of Pharmacy, Hawler Medical University and approval was granted before conducting the study (Approval no. 1/2013). The study was performed under the supervision of the physician. All the procedure was informed to the patients in their native language, and informed verbal consents were taken from them. The patients were followed up weekly for evaluation any side effect or problem may the treatment cause.

\section{Criteria for selecting patients}

For the psoriatic patient, the following criteria of selection were considered: Psoriatic patients with a history of inadequate control of psoriasis with synthetic drugs, a patient of either sex (male or female) between ages of $15-50$ years, not pregnant or nursing patients, not suffering from another skin disease.

\section{Phytochemical analysis \\ Estimation of total phenolic content by} gallic acid

Total phenolic contents were determined according to the Folin-Ciocalteu method with slight modifications. ${ }^{12,13}$ The extract $(100 \mu \mathrm{L})$ was mixed with $1.5 \mathrm{~mL}$ of Folin-Ciocalteu reagent and kept for $5 \mathrm{~min}$, then $4 \mathrm{ml}$ of $20 \%$ sodium carbonate solution was added and diluted to $10 \mathrm{~m} /$ with distilled water. The mixture was kept for 30 min and absorbance was measured at $738 \mathrm{~nm}$. Total phenolic contents were evaluated by calibration curve obtained by measuring the absorbance of the known concentrations of gallic acid standard 
https://doi.org/10.15218/zjms.2017.014

solutions ranging from $1-10 \mu \mathrm{g} / \mathrm{ml}$. The results were calculated as $\mu \mathrm{g}$ gallic acid equivalent (GAE) per gram dry powder.

Extract preparation for TLC and HPLC analysis

One gm of dried R. hemisphaerica stem powder was extracted with ethanol $80 \%$ using ultrasonic assisted extractor for $1 \mathrm{hr}^{9}$ Then, it was filtered and left for drying; it was then dissolved in $10 \mathrm{ml}(5 \%) \mathrm{HCl}$ and refluxed for $1 \mathrm{hr}$, liquid-liquid fractionation using chloroform $(10 \times 3 \mathrm{ml})$ resulted an organic fraction, ${ }^{14}$ on drying in vacuum that was used for evaluation of phenolic acid constituents by TLC and HPLC. The organic extract was filtered through a $0.45-\mu \mathrm{m}$ membrane before injection into the HPLC system.

\section{TLC analysis}

Identification of rosmarinic acid in chloroform fraction of $\mathrm{R}$. hemisphaerica stem extract was carried out by TLC using aluminum plates of silica gel GF254 as a stationary phase and toluene: ethyl acetate: formic acid (2:8:1) as a mobile phase. $^{15}$

\section{HPLC analysis}

All chemical reagents used for analysis were analytical or HPLC Grade (99.99\%). Acetonitrile and formic acid were purchased from Scharlauchemie, S.A., Europian Union. Ultra-pure water was used for sample preparation and preparation of mobile phases for HPLC analysis. Rosmarinic acid as a standard material was purchased from Chroma Dex, USA.

Preparation of stock and standard solutions

Rosmarinic acid $(1 \mathrm{mg})$, was accurately weighed into a $5 \mathrm{ml}$ volumetric flask, dissolved in acetonitrile: water (1:1) and filled up to volume for preparing stock solutions. Standard solutions were prepared for each compound at five different concentration levels $(200,100,50$, 10 and $5 \mu \mathrm{g}$ ) in $5 \mathrm{ml}$ volumetric flasks for the establishment of calibration curves.

\section{Chromatographic condition}

The quantitative and qualitative analyses of rosmarinic acid were performed on Knauer
HPLC instrument equipped with Chrom Gate HPLC software provided by Knauer which was used with Eurospher 100, C18 column $(4.6 \mathrm{~mm}$ i.d. $\times 250 \mathrm{~mm}, 5 \mathrm{~mm})$ and UV/Visible detector. The flow rate of the mobile phase for rosmarinic acid was kept at $1 \mathrm{ml} / \mathrm{min}$. Mobile phase $A$ was acetonitrile and B water containing $(0.5 \%$ formic acid and $2.5 \%$ acetonitrile) isocratic conditions were as $30 \% \mathrm{~A}$ and $70 \% \mathrm{~B}$. The temperature of the column was controlled at $30{ }^{\circ} \mathrm{C}$. Injection volume was $20 \mu \mathrm{l}$, and the detection wavelength was set to $254 \mathrm{~nm} .{ }^{16}$

\section{Validation method}

The developed HPLC method was validated in term of linearity, accuracy, precision, limits of detection (LOD) and limits of quantification (LOQ). Validation of the method was performed as recommended by the International Conference on Harmonization (ICH) guidelines. $^{17,18}$

\section{Statistical analysis}

Data were statistically analyzed using the statistical package for the social sciences (version 10.0). Data within the same treatment group were compared using paired-samples t-test, values were considered to be significantly different when the $P$ value was $<0.01$ and 0.05 .

\section{Results}

\section{Antipsoriatic evaluation}

By clinical and histopathological examination, all criteria of psoriasis in all 20 cases identified and the number of inflammatory cells was counted by per high power field, the results are shown in Table 1. The epidermises are showing hyperkeratosis, parakeratosis, acanthosis with granular layer degeneration in addition to positive Munro's and Kogoj's abscesses as shown in figure (1A, $2 A$, and $3 A$ ). After three weeks of treatment with $R$. hemisphaerica stem extract a significant change in the number of inflammatory cells was seen $(P<0.01)$ when compared before treatment. During follow-up, it was identified that both Munro's and 
Kogoj's abscesses gradually disappeared as shown in Figure 1B, 2B, and 3B,

Table 1: The effect of $\mathrm{R}$. hemisphaerica stems extract on inflammatory cells in skin biopsy (Mean \pm SD).

\begin{tabular}{lccccc}
\hline $\begin{array}{l}\text { Treatment period } \\
\text { (Week) }\end{array}$ & PMN & Lymphocytes & Histiocyte & Fibroblast & $\boldsymbol{P}$ value \\
\hline Before treatment & $25 \pm 1.33$ & $5 \pm 0.55$ & $3 \pm 0.74$ & $2 \pm 0.83$ & \\
Week 1 & $15 \pm 0.39$ & $10 \pm 0.45$ & $8 \pm 0.16$ & $5 \pm 1.20$ & 0.04 \\
Week 2 & $10 \pm 0.79$ & $15 \pm 0.89$ & $12 \pm 0.80$ & $10 \pm 0.72$ & 0.065 \\
Week3 & $3 \pm 0.72$ & $10 \pm 0.22$ & $5 \pm 1.33$ & $10 \pm 0.80$ & 0.0071 \\
\hline
\end{tabular}

PMN: polymorph neutrophils
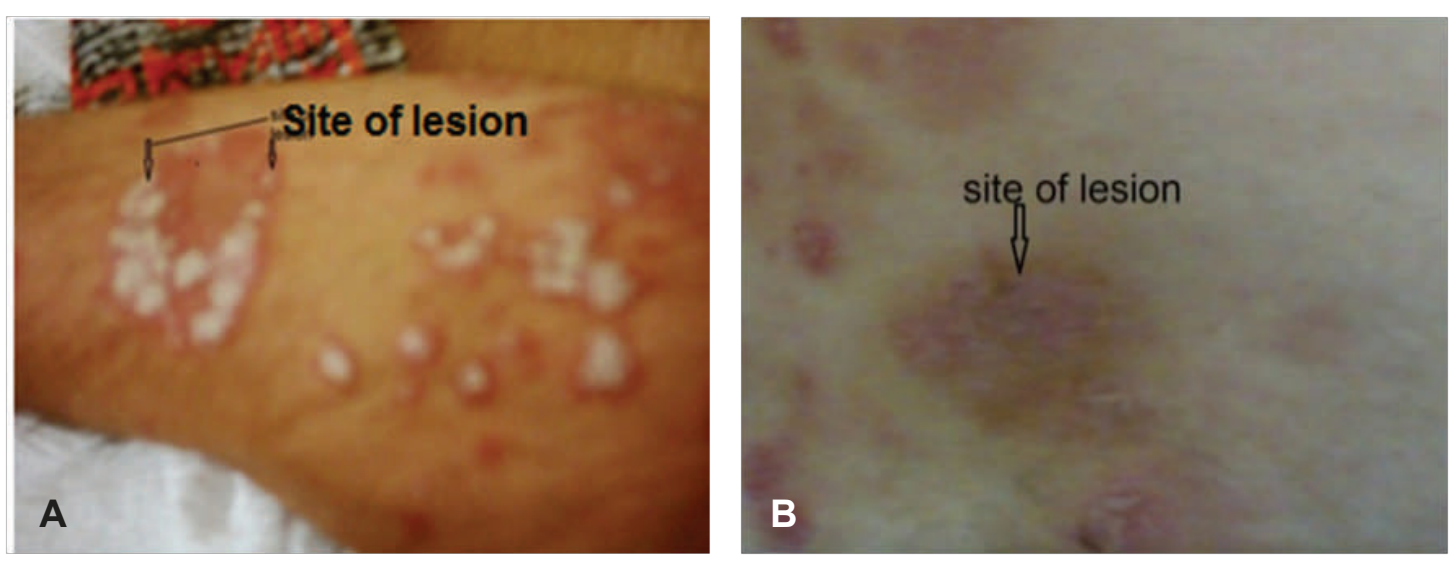

Figure 1: Psoriasis of the forearm,; A, Before treatment; B, Two weeks after treatment.
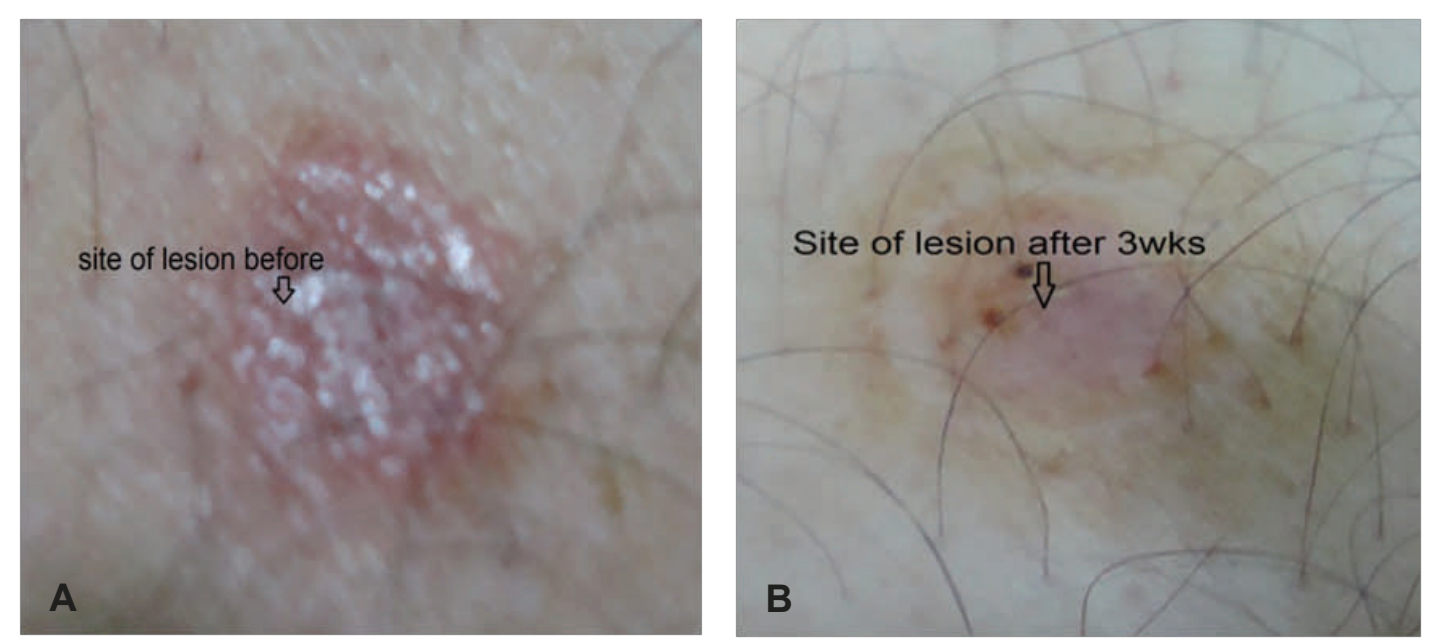

Figure 2: Psoriasis of leg; A, Before treatment; B, Three weeks after treatament. 
https://doi.org/10.15218/zjms.2017.014

the granular layer gradually recovered with increased thickness of the suprapapillary epidermis. By the end of the $3^{\text {rd }}$ week, it returned to normal. The inflammatory cells are gradually decreased in number, started by polymorph neutrophils (PMN) ended by the disappearance of histiocytes as shown in Figure 3C.
Total phenolic contents

The total phenolic content of the ethanolic extract of the stem $R$. hemisphaerica was estimated to be $205.625 \mu \mathrm{g}$ gallic acid equivalentl $\mathrm{gm}$ of sample extract (GAEl gm) using the standard calibration curve equation ( $y=0.016 x-0.008)$ as shown in Figure 4.
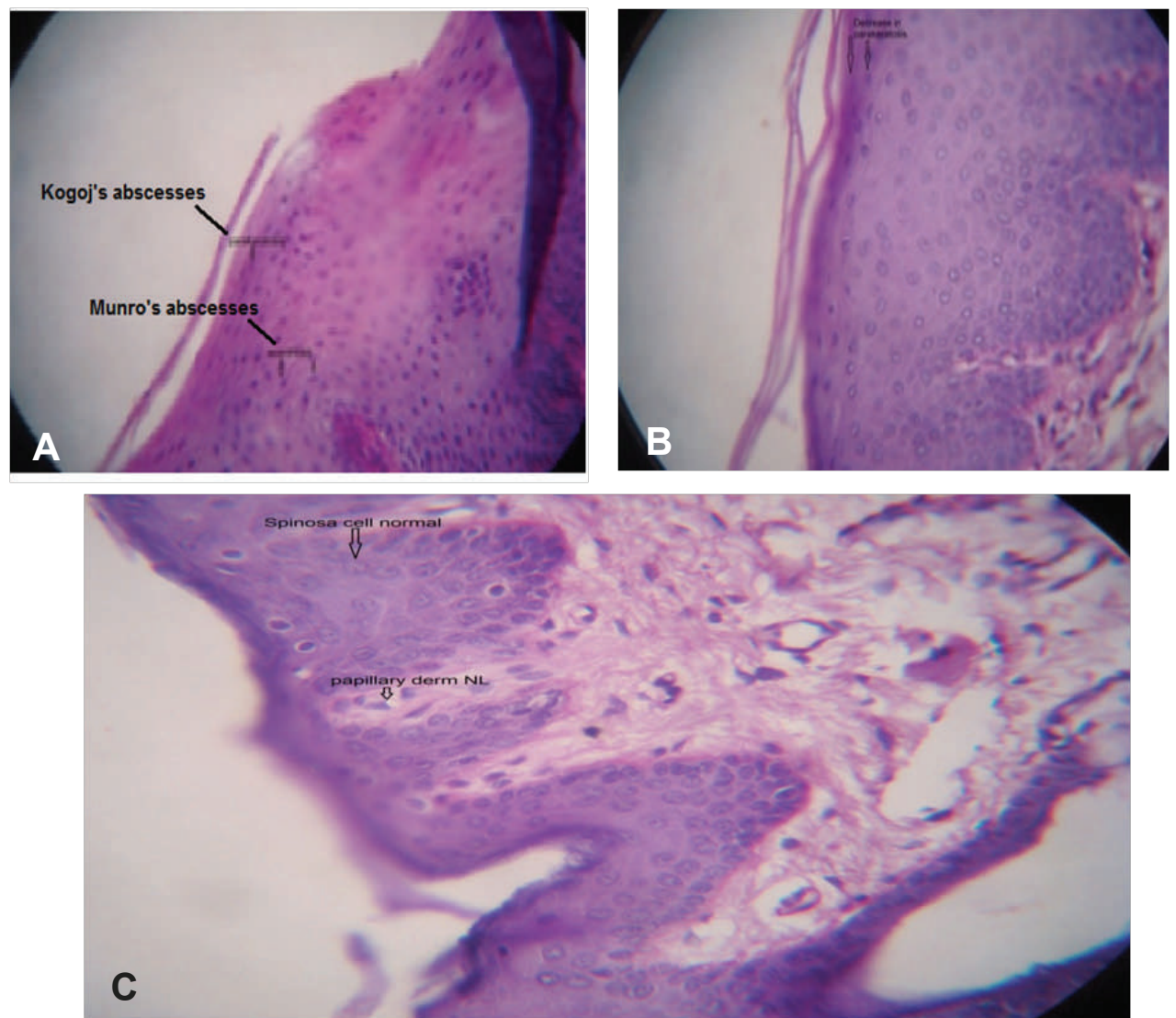

Figure 3: Microscopic picture of psoriasis (H\&E) stain $\mathrm{x} 40 ; \mathrm{A}$, Before treatment; B, After 2 weeks of treatment; C, After 3 weeks of treatment.

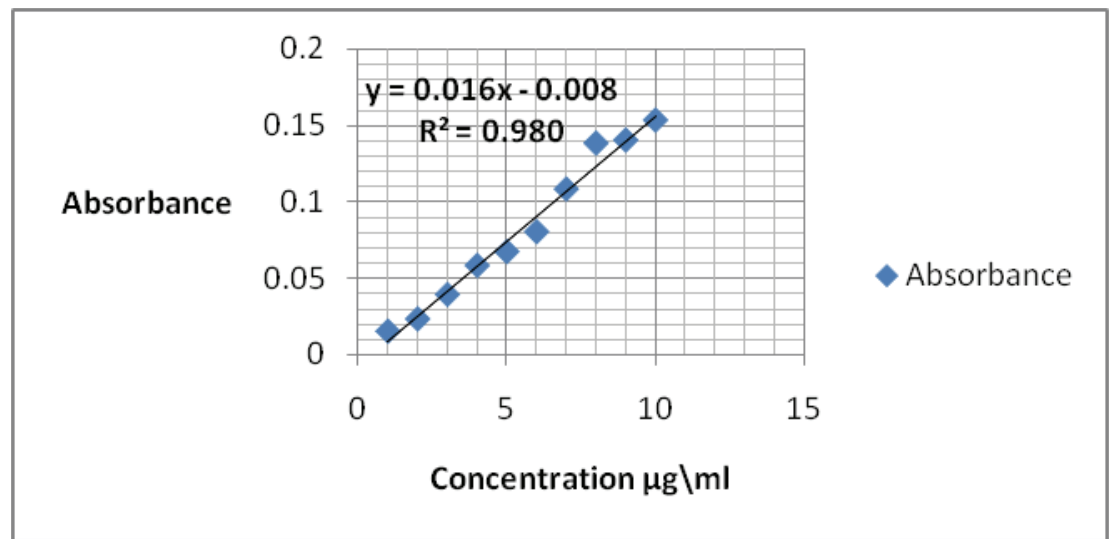

Figure 4: Calibration curve of gallic acid. 
Identification of rosmarinic acid by TLC The results of TLC of the chloroform fraction obtained from the dried stem of $R$. hemisphaerica confirms the presence of rosmarinic acid in stem extract with retardation factor (Rf) value of 0.59 in comparison with standard $\mathrm{R} f$ value 0.61 and appear as blue spot as shown in figure 5 .

HPLC analysis

The identification and quantification study for rosmarinic acid was performed on Knauer HPLC instrument, C18 column and UV/Visible detector recording at $254 \mathrm{~nm}$ for chloroform extract. An isocratic system acetonitrile: water (30:70) was chosen to minimize the variation of the baseline and ghost peaks. Representative chromatograms are shown in figure 6 which indicated the presence of rosmarinic acid.

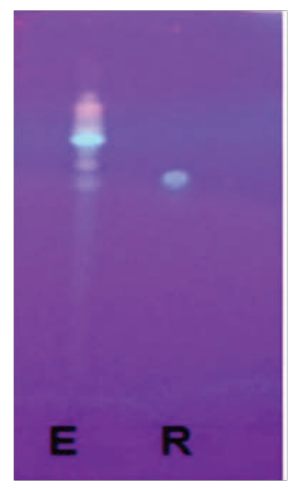

Figure 5: TLC of stem extracts of $R$. hemisphaerica detected by UV-light at $366 \mathrm{~nm}(\mathrm{E}$ : chloroform fraction, R: rosmarinic acid standard).

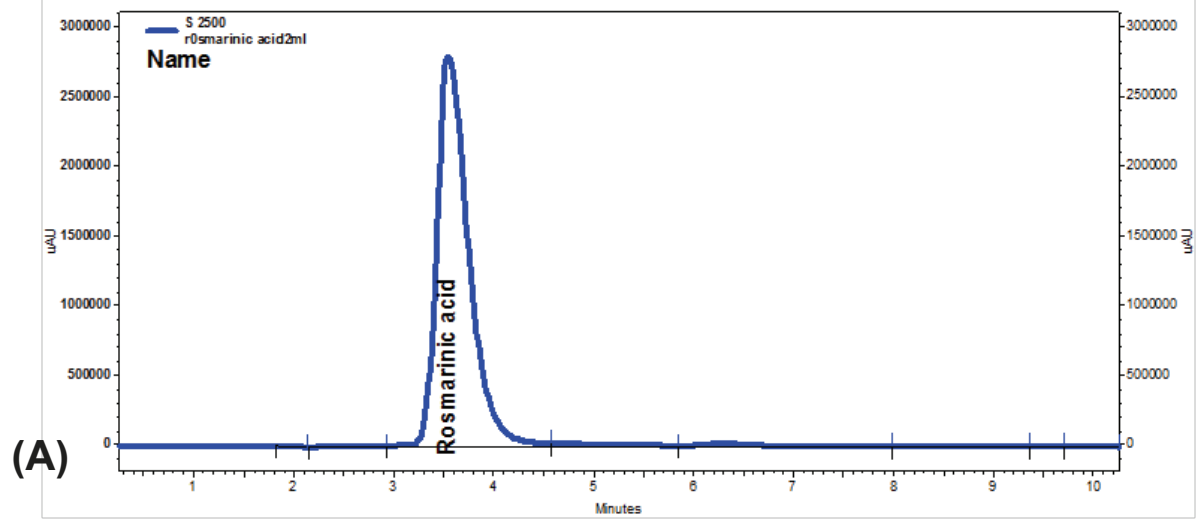

(B)

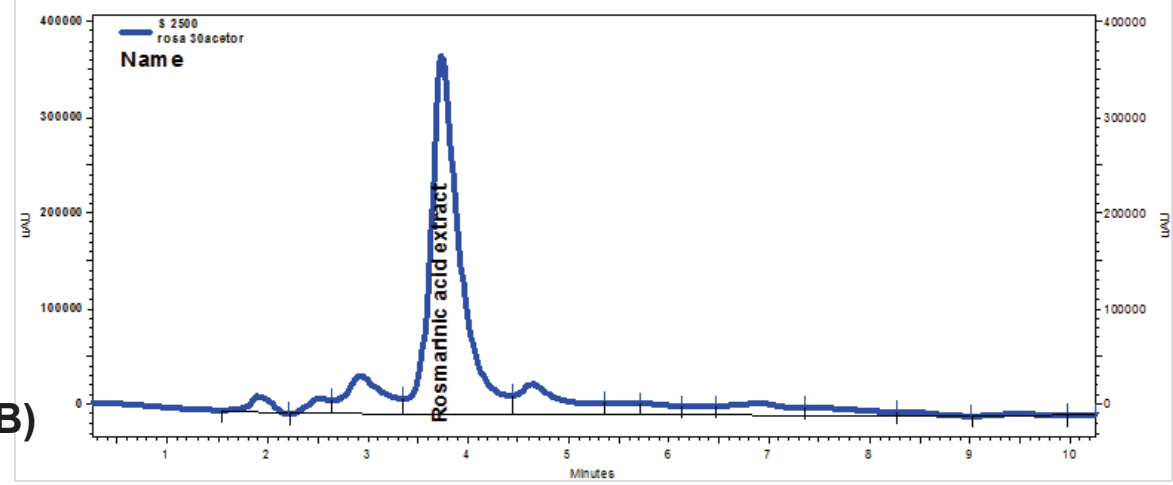

Figure 6: HPLC chromatograms of A: Rosmarinic acid standard compound; B: R.hemisphaerica extract. 
The HPLC method was sensitive and while the accuracy of the proposed method the validation data are presented in Table 3. The intraday and interday precision expressed in term of relative standard deviation (RSD) $(n=3)$ at concentrations of $50,100,200 \mu \mathrm{g} / \mathrm{ml}$, was expressed as the recovery of a standard compound as shown in Table 4. The quantity of rosmarinic acid in $R$. hemisphearica extract was $0.024 \%$.

Table 3: System suitability and validation parameters.

\begin{tabular}{lc}
\hline Parameters & Rosmarinic acid \\
\hline Linearity range $(\mu \mathrm{g} / \mathrm{ml})$ & $5-200$ \\
Regression equation & $\mathrm{Y}=\mathrm{aX}-\mathrm{b}$ \\
Correlation coefficient $(\mathrm{r})$ & 0.998 \\
Slope & 0.4039 \\
Intercept & 0.7171 \\
SE of intercept & 0.7809 \\
SD of intercept & 1.7461 \\
LOD $(\mu \mathrm{g} / \mathrm{ml})$ & 14.26 \\
LOQ $(\mu \mathrm{g} / \mathrm{ml})$ & 43.23 \\
$\mathrm{Rt}$ & 3.4 \\
\hline
\end{tabular}

Table 4: Precision and recovery data of HPLC methods.

\begin{tabular}{|c|c|c|c|c|c|}
\hline \multirow{2}{*}{ Compound } & \multirow{2}{*}{$\begin{array}{c}\text { Amount } \\
\text { added }(\mu \mathrm{g} / \mathrm{ml})\end{array}$} & \multirow{2}{*}{$\begin{array}{c}\text { Amount } \\
\text { recovered }(\mu \mathrm{g} / \mathrm{ml})^{\mathrm{a}}\end{array}$} & \multirow{2}{*}{ Recovery $(\%)^{a}$} & \multicolumn{2}{|c|}{ RSD (\%) } \\
\hline & & & & Intra day ${ }^{b}$ & Inter dayc \\
\hline \multirow[t]{3}{*}{ Rosmarinic acid } & 50 & $49.60 \pm 0.69$ & $100.01 \pm 0.69$ & 1.39 & 1.77 \\
\hline & 100 & $100.60 \pm 1.82$ & $99.01 \pm 1.82$ & 1.81 & 2.05 \\
\hline & 200 & $199.81 \pm 3.65$ & $97.91 \pm 3.65$ & 1.82 & 1.86 \\
\hline \multicolumn{6}{|c|}{$\begin{array}{l}\text { a Mean } \pm \text { SD }(n=3) \\
\text { bSamples were analyzed three times a day } \\
\text { 'Sample were analyzed three times over two consecutive days }\end{array}$} \\
\hline
\end{tabular}




\section{Discussion}

Histopathology examination confirmed that all patients who received the treatment were cured and the lesion disappeared, the healing process started by a decline in PMN infiltration probably due to anti-inflammatory and antioxidant effects of rosmarinic acid. Antioxidant activity of phenolic acid is due to the ability to suppress the generation of free radicals, thus reducing the rate of oxidation by inhibiting the formation of or deactivating the active species and precursors of free radicals. $^{19}$ The natural antioxidant rosmarinic acid spontaneously penetrates membranes to inhibit lipid peroxidation in situ. ${ }^{20}$ Changes such as decrease in mononuclear cell infiltration may be induced by anti-inflammatory effects of polyphenolic metabolites, ${ }^{21}$ while decline in squamous cell proliferation and disappearance of scales may be attributed to antitumor effects of polyphenolics on cell cycle $^{22}$ because in psoriasis the cell cycle will be reduced to 10-15 days while normal cell cycle in epidermal epithelial cells is about 30 days. Total phenolic content which was estimated for the ethanolic extract of stem $R$. hemisphearica was lower than the total phenolic content recorded by ${ }^{3}$ for the methanolic and aqueous extracts of the flowers of the same plant. In the present study, we used ultrasonic assisted extractor method which is a modern method for extraction of active constituents from the plant in which produce sound waves that create cavitations' bubbles near the sample tissue, which breaks down to disrupt cell walls, thereby releasing cell contents. Ultrasound has been used in both static and dynamic modes to extract phenolics from plant materials. A static system is a closed-vessel extraction for which no continuous transfer of solvent occurs. In dynamic extraction, fresh solvent is supplied continuously, which allows efficient adsorption of analytes and their effective transfer from the extraction vessel. Continuous transfer of extracted analytes prevents degradation of any thermolabile compounds by the heat associated with sonication. ${ }^{23}$ The qualitative and quantitative analysis of rosmarinic acid content in chloroform extract $R$. hemisphearica in Kurdistan were performed for the first time. The presence of phenolic compounds supported by previously recorded data, ${ }^{3}$ but no previous qualitative and quantitative study on the type of phenolic acids in $R$. hemisphearica were conducted. The results revealed the presence of rosmarinic acid in the chloroform extract as shown in figure 6 . Calibration curve of standard solution was obtained by the external standard method on five dilutions with three injections per level was linear over concentration 5-200 $\mu \mathrm{g} / \mathrm{ml}$ as shown in Table 2 and yielded correlation coefficients 0.998 confirming the linear relationship between the concentration and area under the curve. LOD and LOQ were calculated as 14.26 and $43.23 \mu \mathrm{g} / \mathrm{ml}$ respectively as present in table 3. Recovery of rosmarinic acid ranged between 100.01-97.91\% showing that the developed methods manifested reliability and accuracy for measurement of rosmarinic acid as shown in Table 4. A repeatability test was performed for a solution at three concentrations 50, 100 and $200 \mu \mathrm{g} / \mathrm{ml}$ in order to estimate intra-day variation in the peak areas and retention times. The highest value for RSD was $2.05 \%(n=3)$ proving good repeatability and reproducibility of the developed method.

Table 2: Calibration data for the proposed HPLC methods.

\begin{tabular}{lcc}
\hline Compound & $\begin{array}{c}\text { Concentration } \\
(\boldsymbol{\mu g} / \mathrm{ml})\end{array}$ & $\begin{array}{c}\text { Peak area } \\
\mathbf{1 0}^{5}(\mathbf{m A U})\end{array}$ \\
\hline & 5 & 2.1 \\
& 10 & 4.06 \\
Rosmarinic & 50 & 17.83 \\
acid & 100 & 39.16 \\
& 200 & 80.66 \\
\hline
\end{tabular}


https://doi.org/10.15218/zjms.2017.014

\section{Conclusion}

$R$. hemisphearica stem was found to reduce inflammation significantly in psoriatic patients. Rosmarinic acid was identified by TLC and HPLC. The healing process of $R$. hemisphearica stem extract is most probably due to anti-inflammatory and antioxidant effects of rosmarinic acid by decreasing free radicals at the site of inflammation. Further works are recommended for the evaluation of antipsoriatic activity on a larger number of cases and isolation and identification of all constituents responsible for this activity.

\section{Acknowledgements}

The authors are gratefully acknowledging the support of the Department of Pharmacognosy, College of Pharmacy, and the College of Medicine, Hawler Medical University.

\section{Conflicts of interest}

The authors report no conflicts of interest.

\section{References}

1. Rechinger HK. Flora Iranica. Rosaceae II: Rosa, J. Zielinski. Graz: Akademische Druck und Verlagsanstalt publishing; 1982. p.8.

2. Zargari A. Medicinal plants, $2^{\text {nd }}$ ed. Tehran: Tehran University Publication; 1991. p.162-4.

3. Kashani AD, Rasooli I, Sharafi SM, Rezaee MB, Nadoushan MRJ, Owlia P. Phytobiological characteristics of Rosa hemisphaerica Herrm. Extract. J Med Plant 2010; 9(6):97-106.

4. Basim E, Basim H. Antibacterial activity of Rosa damascena essential oil. Fitoterapia 2003; 74:394 -6 .

5. Boskabady $\mathrm{MH}$, Kiani S, Rakhshandah $\mathrm{H}$. Relaxant effects of Rosa damascena on guinea pig tracheal chains and its possible mechanism(s). J Ethnopharmacol 1995; 106:377-82.

6. Orhan DD, Hartevio glu A, K"upeli E, Yesilada E. In vivo anti-inflammatory and antinociceptive activity of the crude extract and fractions from Rosa canina L. fruits. J Ethnopharmacol 2007; 112:394-400.

7. Safaei-Ghomi J, Bamoniri A, Hatami A, Batooli $H$. Determination of volatile components in Iranian Rosa hemisphaerica. Chem Nat Comp 2007; 43 (6):738-40.

8. Gudjonsson JE, Elder JT. Psoriasis: epidemiology. Clin Dermatol 2007; 25(6):535-46.

9. Alupuli A, Calinescu I,Lavric V. Ultrasonic vs. microwave extraction intensification of active principles from medicinal plants. AIDIC conference series; 2009.
10. Ramanauskienè $\mathrm{K}$, Žilius $\mathrm{M}$, Briedis $\mathrm{V}$. Rheological and biopharmaceutical studies of the experimental propolis semisolid preparations. konferencijosmedžiaga 2012; 18(2):181-8.

11. Arain M, Campbe JM, Cooper LC, Lancaster AG. What is a pilot or feasibility study? A review of current practice and editorial policy. BMC Med Res Method 2010; 10(67):1-7.

12. Mcdonald S, Prenzler PD, Autolovich M, Robards K. Phenolic content and antioxidant activity of olive oil extracts. Food Chem 2001; 73:73-84.

13. Adesegun SA, Fajana A, Orabueze $\mathrm{Cl}$, Coker HAB. Evaluation of antioxidant properties phaulopsis fascisepala. Evid Based Complement Alternat Med 2009; 6:227-31.

14. Khoddami A, Wilkes AM and Roberts HT. Techniques for analysis of plant phenolic compounds. Molecules 2013; 18:2328-75.

15. Pavel M, Voştinaru O, Mogoşanu C, Ghibu S. Phytochemical and pharmacological research on some extracts obtained from Serpylli herba. Farmacia 2011; 59(1):77-83.

16. Nour V, Trandafir I,Cosmulescu S. HPLC Determination of phenolic acids, flavonoids, and juglone in walnut leaves. J Chrom Sci 2012; 6:1-8.

17. International Conference on Harmonization, guideline Q2A, Text on validation of analytical procedures: Methodology. USA: Federal register publishing; 1995. p. 11260-2.

18. International Conference on Harmonization, guideline Q2B, validation of analytical procedures: Methodology. USA: Federal register publishing; 1997. p. 27463-7.

19. Tsao R. Chemistry and biochemistry of dietary polyphenols. Nutrients 2010; 2:1231-46.

20. Fadel O, El Kirat K, Morandat S. Anti-inflammatory actions of flavonoids and structural requirements for new design. Biochimica Biophysica Acta 2011; 1808:2973-80.

21. Theoharides TC, Alexandrakis M, Kempuraj D, Lytinas M. The antitumor activities of flavonoids. Int Immunopathology Pharmacol 2001; 14(3); 119-27.

22. Kandaswami C, Lee LT, Lee PP, Hwang JJ, Ke Fc, Huang $T$, et al. The antitumor activities of flavonoids. In vivo 2005; 19(5):895-909.

23. Vinatoru M. An overview of the ultrasonically assisted extraction of bioactive principles from herbs. Ultrason Sonochem 2001; 8:303-13. 